\title{
Supporting human service workers following the Canterbury earthquakes
}

Kate van Heugten

Kate van Heugten is an Associate Professor in the Department of Human Services and Social Work in the School of Social and Political Sciences at the University of Canterbury, Christchurch.

\section{Abstract}

In the aftermath of the 2010 and 2011 earthquakes in Canterbury, many human service workers, including social workers, struggled to meet the needs of distressed service users at the same time as they were dealing with the personal impacts of these disasters. The consequences of the earthquakes have been particularly complex and long lasting. There is no known end point for the aftershocks, and the socio-economic repercussions continue to unfold. Forty-three human service workers participated in qualitative research interviews during late 2011. The challenges they identified included the taxing nature of work involving emotional labour in a context of shared trauma; environmental stress; complex demands and fewer resources; ethical dilemmas and moral distress. Many participants re-evaluated their personal and professional priorities, and questioned the fit of those priorities with the values of their employing organisations. In doing so, some had become disenchanted, particularly if they felt they had not been consulted about decisions that impacted on their work with service users. By contrast, some participants expressed a strong sense of loyalty and engagement with organisations where workplace culture was experienced as reflective of the importance of caring for human needs and relationships.

\section{Introduction}

Social workers and other human service workers experience high levels of stress when demands they face outstrip the resources available to them (van Heugten, 2011). Unrelieved stress may lead to physical and psychological ill health, exhaustion and finally burnout. Burnout causes workers to lose their capacity for empathy with service users, emotionally withdraw and potentially leave their employment (van Heugten, 2011). It is expectable that working in the long-term aftermath of community disasters, such as the earthquakes that occurred in Canterbury in 2010 and 2011, will result in additional pressures on human service workers as they endeavour to assist service users with complex problems, while resources for doing so may be limited, and their personal lives are impacted (van Heugten, 2012).

There have been many significant earthquake aftershocks in the Canterbury region since September 2010, and these continue to this day. There were two particularly damaging earthquakes. The first occurred at 4:35 am on 4 September 2010, and measured 7.1 on the Richter scale. Many buildings were damaged but no loss of life was directly attributable to the event. The second occurred at 12:51 pm on Tuesday, 22 February 2011. Although, the 6.3 earthquake was less severe, it was located closer to the centre of the city of Christchurch where ground shaking was significant. At this time, many people were at work, at school, or in the city's shops 
and eateries. There were major building collapses and 185 people lost their lives (Stylianou, 2012). There were also many people who sustained life changing injuries, including loss of limbs and spinal cord injuries (Brooker, 2011). The extent of the devastation was immediately obvious to those who worked in the central city. Other citizens had to glean information from cell phone messages, radio and television reports once power and communication services were restored to their areas. The devastated centre of the city became a 'red zone' that was inaccessible to the public. Soon residential areas were also assigned colours 'red', 'orange', 'green' and 'white' to rank the destruction of home and land, from irredeemable, to repairable, unaffected or 'undetermined' (New Zealand Government, 2011).

Having previously undertaken research into workplace stress amongst social workers, I responded to suggestions that I should undertake research to explore the challenges now being faced by human service workers. I undertook this research in late 2011, when there were still frequent aftershocks, but the immediate emergency phases following the most devastating earthquakes had passed.

\section{Methods}

I determined that a qualitative research project would be the most appropriate means of investigating the post-earthquake workplace experiences of human service workers. Semi-structured interviews allow new and unexpected information to emerge, as the researcher does not set out to test pre-conceived hypotheses. I employed situational analysis to analyse the data. Situational analysis is akin to grounded theory in its emphasis on memo writing, exhaustive coding and categorising of data, and inductive approach to theorising (Glaser \& Strauss, 1967). It differs from grounded theory in that it encourages researchers to more deliberately consider relationships of power, and the impacts of economics, politics, and environmental conditions, even if these have not been overtly commented upon by research participants (Clarke, 2005).

I was interested in the experiences of human service workers and managers more generally, not only those of social workers. A key characteristic of the group of workers invited to participate in the research was that they had carried professional responsibilities for the wellbeing of others, while being members themselves of the community in which the disaster had taken place.

The University of Canterbury's Human Ethics Committee approved the study. Because participants might potentially recall distressing events, I compiled a list of support organisations to which participants could be referred if they wanted this. The semi-structured conversational approach enabled participants to control the depth of the exploration, and it was my impression, and I was told by participants, that the interviews were found to be supportive rather than traumatising, even if distressing experiences were recounted.

I planned to make an initial call for participants via the Aotearoa New Zealand Association of Social Workers (ANZASW), and then to expand upon this through other social service networks. The call for participants that was emailed out by ANZASW resulted in approximately 50 replies. I commenced interviews and found that, due to members having alerted others to the research, the participants already included non-social workers. It was therefore not necessary to make a further call for participants. 
In grounded (and situational) research, interviews and analysis proceed together. I departed from that expectation when I quickly moved to complete as many interviews as possible, 43 in all, from late September to early December 2011. I hastened to conduct the interviews because I was concerned that memories might decay, and also that people might be less interested in participating after the Christmas holidays. I thought that many citizens might hope to leave thoughts of earthquakes in their past.

Of the 43 participants, seven were men and 36 were women. Twenty-nine specified their ethnicity as New Zealand European, six as Māori, one as New Zealand European/New Zealand Māori and two as New Zealand Samoan. Three were Anglophone immigrants, and two were immigrants from continental Europe. Their ages reflected the ageing human service workforce: only three participants were aged 25-35, nine were aged 36-45 and 31 were over 45 years of age. Twenty-eight participants were employed as frontline workers, and 15 were in managerial or supervisory roles. Most had professional qualifications, including qualifications in social work, psychology, education and human resource management. Participants were employed in government, quasi government, and non-government organisations (NGO), private practices and manufacturing industries. Fields of practice included health, mental health, child protection, justice, education services and human resources.

I started interviews with a basic open-ended question, inviting participants to reflect on their experiences of workplace challenges and opportunities resulting from the earthquakes. I stated that they were free to talk from a personal or more organisational or political perspective. Interviews lasted approximately one hour. At the time of writing this article, only a subset of the interviews has been transcribed and checked by the participants, and I have cited only those transcripts. My analysis is incomplete, and feedback, including comments on seminars and preliminary writing, assists me in its ongoing development.

\section{The immediate aftermath of the earthquakes}

In the immediate aftermath of the earthquakes, emergency response teams had swung into action to search for and assist people; restore life support systems, including power and water supplies; and secure property. By late 2011, participants' dominant recollections were of the 22 February 2011 earthquake, which struck when most of them had been at work. Their responses depended on their roles, the needs of the people around them, and, if given, instructions from employers. Those employed at designated emergency response centres often became involved in triaging the injured and directing people who were searching for loved ones. Others had volunteered at field stations. As one participant said, 'Also, I mean adrenalin had kicked in, we weren't tired. Mm, it was pretty full on with, you know, the cars, trucks, trailers, station wagons pulling up with people in it'. Participants with management responsibilities supported staff, usually by sending them home; identified and planned for at-risk service users; and secured work premises. Many participants feared for the safety of family and friends and left work to check on them, but it took hours to discover whether they were alright.

During the following days, organisations, including ANZASW, called for volunteers for the emergency relief effort. Several participants had accepted that challenge. Tasks included door knocking to encourage people to evacuate homes that were in danger of collapse, and working in welfare centres that had been set up to house, feed and psychologically comfort 
distressed residents. The work could involve extremely long hours, and there appeared to have been no formal follow-up to check on volunteers' wellbeing.

And so you didn't know what you were going to [find] when you knocked on the door. ... we'd start at 7 in the morning and we'd finish at 7 at night ... And, funny, I look back on that and think that, in a way I didn't realise at the time, but it was it was very, very stressful in the wake of having just been through my own trauma and stress ... And in some ways it was great because it completely distracted you from the reality of what was happening for yourself, and I probably feel I'm feeling the impact of February much more now than I did then.

Although most participants felt pleased to have been able to help, the international literature suggests that emergency responders function and recover better if they are trained and prepared for what to expect in terms of likely scenarios. They should be followed up, and if necessary supported, in the aftermath (Guo, et al., 2004).

Problems arose if workers felt their employers had pressured them to return to work early, and had forced them to sideline their own family needs. Some participants observed that workers' efforts had been taken for granted and that these still remained unrecognised: 'It was very much put back onto the workers and 'these are our expectations and step up'. People are furious about that. It's like we've given and given, and busted our guts some of us, you know'.

By contrast, participants felt well looked after when managers had made it clear that 'family comes first'; when people were encouraged to take leave when they needed this; and when they felt they had been trusted to work to their capacity.

\section{Longer-term impacts}

By the time of the interviews, the immediate adrenalin-fuelled crisis phase had passed. Participants commonly complained of tiredness, sleeplessness, and coughs and colds that would not go away. They cried more easily, or were less patient with colleagues and clients. Some had begun to feel disenchanted with their employers, but only a few were actively searching for other jobs.

Specific problematic features of work included the toll taken by emotional labour; disruptions to the physical environment, including workplaces; increased workload demands or complexity of work with reduced resources; ethical dilemmas and moral distress; and questions about the fit of professional or personal values with organisational directions.

\section{Emotional labour}

Human service work involves emotional labour (Dwyer, 2007) because in order to understand services users' experiences of their situations, workers have to empathically engage with them. This is more taxing in a context of shared trauma (Tosone, Nuttman-Shwartz, \& Stephens, 2012), such as existed following the Canterbury earthquakes, when anxieties about aftershocks, housing, jobs and children's schooling were held in common. Working with more distressed people, whether customers, clients or students, requires work to be better paced, with more breaks and places to escape to rest and reflect before focusing on the next task. The following participant was able to pace her work, but, due to stresses at home, still struggled to cope: 
It's too horrible to look at as a whole, so you just think, 'If I can make it through this week I'll be okay, for me'. And then suddenly the end of the week comes, and you think, okay that wasn't as bad as I thought.

Although many participants identified that they were feeling exhausted, they used downward comparisons to explain that their situation was not as bad as that of others. Downward comparison may lead people to battle on, rather than ask for help (Sullivan \& Wong, 2011). When asked about support from supervisors, several participants noted that the frequency of supervision had been reduced since the earthquakes, or that their supervisors were struggling emotionally. A few participants sought counselling assistance. Participants appreciated collegial support and employers' efforts to organise social events.

\section{Environmental stress}

The earthquakes had disrupted the environments in which participants lived and worked. Cramped, open-plan workspaces lacked privacy for meetings or telephone conversations. Some participants worried that service users might be at risk, because case-related inquiries might be less thoroughly pursued, relevant collegial communications reduced and difficult discussions with supervisors avoided due to a shortage of confidential meeting rooms. Along with being less private, shared workspaces were felt to be sterile. In the aftermath of disasters, people can be comforted by having personal items such as photographs on desks or walls, and it was disturbing to hear that some participants' managers had discouraged that. Previously cohesive teams were fragmented because members were spread across sites, or because they were mixed in with other people who were doing unrelated work. Multiple relocations were common as more buildings were found to be unsafe over time. The moves could be unsettling, but if the relocation was to a low rise, this relieved those workers who were afraid to be in multi-storied buildings.

Several participants were working from their homes, which were not generally set up for this purpose. As has been found by other researchers, boundary keeping around personal and work time and space was also difficult (Hartig, Johansson, \& Kylin, 2003). Children and grandchildren needed to be kept away from corners of living rooms now dominated by computers, and were made to stay quiet during telephone calls. Working from home could be expensive, and some participants complained that their employers failed to adequately reimburse internet use and printing costs. Some participants were concerned that since they had accepted inadequate emergency accommodation, bosses now expected them to be satisfied with poorer facilities.

Making home visits and attending meetings had become time consuming because many roads were damaged and routes constantly changed as repairs to infrastructure, such as sewerage systems, led to street closures. Driving to and from work also reminded participants of the extent of the devastation of the city and the far reaching effects on its people.

But I think the worst, the worst part that I'm still finding too, is still going into the areas. ... because we're out on the road so much and we're going to the areas that are still ... a mess, and [it] ... just gets quite depressing actually.

In relation to self care, many participants talked about the loss of entertainment and exercise facilities since their favourite theatres, restaurants, gymnasiums and pools had been closed. 


\section{Complex demands and fewer resources}

Hochwarter, Laird, and Brouer (2008) reviewed the impacts of hurricanes in the Gulf of Mexico and found that, provided there are resources to meet them, increased work demands following disasters may heighten job satisfaction. In the aftermath of the Canterbury earthquakes, however, resources were reduced. Many computers, printers, desks, client files and training materials were lost. Colleagues and volunteers left Christchurch, became unwell or decided to concentrate on their own family needs. While some clients also departed, and this might impact negatively on an organisation's funding, remaining ones often had more complex needs:

Probably ... half my case load who had been least stable would've decompensated over that time. So it was quite hard work when I look back, when I think back about how many people haven't done well this year.

Administrative workloads became more difficult to manage:

And the other stress of course is the paperwork associated with it. I feel like I haven't actually, it might sound terrible, fully caught up this year. I feel like I'm always about six weeks behind and I've never had that before. I've always been reasonably conscientious, but it's just, there's still the aftermath of it.

Participants who were in middle management roles talked about their continuing efforts to persuade head office staff and funders located in other cities, that local stresses were still ongoing. They noted that some imposed reporting templates poorly reflected the actual work needing to be done.

\section{Ethical dilemmas and moral distress}

The literature around disaster management infrequently addresses the ethical dilemmas that arise. This is despite the impact on workers of having to make, or carry out, extremely difficult decisions about who can be helped and who will miss out (Linzer, Sweifach, \& HeftLaPorte, 2008). We are familiar with international examples of crises in which food, water and medicine have been in short supply, but close to home, participants grieved over the deaths of older persons who had been relocated out of the city and away from family, and over their inability to help everyone. They talked about how they had turned away from suffering at times when they felt wearied or helpless. Such experiences are not uncommon in disaster contexts, but may be hidden out of shame, and result in remorse, self doubt and moral distress (van Heugten, 2011).

In the context of financial pressures, several participants talked about the dilemmas posed by money having been made available to undertake earthquake-related work, such as trauma counselling. This work might not fit with the expertise of staff, nor meet the real needs of the organisation's traditional service users. On the other hand, not taking on the new work could be costly. Alternative solutions, such as representing real needs as if they fitted with the projects that were being funded, also gave rise to ethical discomfort.

By the time of the interviews, several participants had become disillusioned with their organisation's communication and consultation processes. It was not uncommon for frontline workers and managers to doubt the motives of decision makers. They expressed their suspicions, that uncertainty, instability and risks were being highlighted in order to promote a false belief that the crisis caused by the earthquakes required previously mooted 
restructuring plans to be more rapidly advanced, leaving little time for consultation. Klein (2007) identified a loss of democratic processes, coupled with an advancement of neoliberal agendas, arising in the aftermath of disasters. When workers begin to believe their values no longer align with those of their employers, they disengage and withdraw (Lloyd, King, \& Chenoweth, 2002). Organisational values and ethical behaviours may be especially important factors in the retention of workers who have experienced life-changing crises and who are subsequently deciding how, and where, to live and work.

\section{Where to from here?}

New Zealand's Health and Safety in Employment Amendment Act 2002 requires employers to attend to employees' needs in relation to stress and fatigue. Employers are required to make reasonable efforts to ameliorate problems, including workload problems. What constitutes reasonable effort is, however, open to dispute. While it is difficult, though not impossible, for employees to take their employers to task in a legal forum, it is predictable that, if post-disaster exhaustion is allowed to continue, burnout will become more inevitable for increasing numbers of otherwise resilient people. A concerned participant said:

It's not rocket science. There's a body of literature in the community that informs us about what we can expect to see, and I'm astonished that managers in some of these places are not, don't have the insight and awareness to be thinking, 'Oh yeah, people have held together, we've had a bit of a honeymoon phase, the busy phase, this is sort of the reality phase of the impact on these people's lives, this is the time we actually need to be very mindful and caring and nurturing of our people so-oh-oh'.

In addition to needing to ensure that workers are given time to recover, responsible organisational managers must take account of the reality that another devastating earthquake or another kind of disaster may occur at any time. If organisations are to respond resiliently to such an event, there must be a store of internal and external resources that can be drawn upon. Local employers may not have factored into their emergency plans, that workers have no reserves that would allow them to repeat their extraordinary efforts of the last few years:

Having been through those experiences I would be clear from the outset about what I could and couldn't do.

Kate: So what you've been doing, you can't do it again?

No. I mean we responded as humans, didn't we, to what had happened. But if we continue to have massive earthquakes we'd have to change what we did. Otherwise we couldn't keep doing our jobs.

As well as talking about difficult challenges, many participants did identify resiliencebuilding organisational practices. In the immediate aftermath, these had included offering practical and social support:

And work really swung into action. So what they did was they set up a system... to make sure, 'Are you okay?' 'Are your family okay?' ‘Anyone injured?' ‘What's your house like?' So within days, they found out who was the most worst affected, did they need re-housing, what support did they need?

Effective helping involved inquiring into the practical needs of all staff members and their families. Workplaces set up washing machines, clothes dryers, freezers, and water tankers. 
Inquiries into emotional wellbeing were normalised, and made on a regular basis with all staff and all managers. Although participants appreciated being told about counselling that was available through Employment Assistance Programmes (EAP) and other services, peer support was more often called upon than formal psychological support. Networks of peer and supervisory support were strengthened, and some organisations paired Christchurch staff with out-of-town 'buddies', taking care not to assume needs or to take over unless asked. Managers of local NGO networked and swapped hints for dealing with difficulties.

Participants commended organisations that prioritised the care of staff over financial returns. One noted: 'I have to say, I'm very proud ... because it's a competitive environment ... it speaks volumes about how we were prioritising the right things at that time'. Another said: 'And those are all the things I've learnt since I started working for this company, and the things that surprise me, is that it has a very, very strong social conscience. And that's helped me'.

Communication needs changed over the post-earthquake recovery period and participants noted the importance of carefully tailoring communication to different workers, and with changing emphasis over time rather than 'broad emails and newsletters to all of the staff' which, whilst well-intentioned, were experienced as 'nothing personal and it's, it's nothing tangible, and that's the difference'. Participants noted that when seeking feedback, for example on staff wellbeing and the effectiveness of organisational endeavours to support them, it was critical to respond to the feedback and make changes to approaches that were reported to be failing. Consultation needed to be genuine, and decision making collaborative, especially about matters that might impact on workers' roles and tasks. When that could not happen, such as during an immediate crisis, explanations should be given as soon as possible. When frontline workers were listened to and trusted to make sensible decisions about immediate and longer-term priorities, they felt valued and energised.

Managers who provided supportive environments educated themselves: They read 'every book there was to be read', and attended workshops and seminars on resilience building. The following participant had done much reflecting about building resilient organisations, and thought it essential to establish shared workplace values and ideals, integrated into reliable customs. He explained his as follows:

Work culture is not much different to ethnic culture ... Ethnic culture is about people feeling safe and feeling as though customs and traditions ... are always there. And if there is a bereavement, or whatever else, there is a custom or a tradition about how we do something. And organisational customs, and values, and traditions, if you do that well, start to provide a very nice culture. And so, ... not that we'd ever want to [go through] that, but the learnings we had, the way we cared for our staff, the way they saw that, has meant that we have a really, really nice workplace. It's one that we can all be proud of. It might not be easy to put down in simple metrics, as to what makes a successful or really great workplace or workplace culture. We have it now, and some of that has been because of all the different minds and knowledge and experiences put in, to be able to say, 'If a situation like this happens, what is the traditional, the traditional way that we should look after our people and care for them'.

He believed that, whilst it should not be the motivating purpose, organisations that developed such a culture would inevitably enhance their reputation because the diligent concern shown for staff would be transmitted into the quality of work, and customers or service users would apprehend that they would be valued too. 
The importance of a workplace ethic that prioritised the care of staff was expressed in various ways in the interviews. Many participants said that, having faced a life-threatening and life-changing disaster, they had re-evaluated what was most important in life. One participant said, 'Life is about the living really, so it's about enjoying it and trying to help the people I work with'. Another summed up as follows:

And I think, you know, that sort of realisation that actually life can be short - and that seems to be a common theme, that actually everyone that I come in contact with are saying, that the material things don't matter so much anymore.

In the aftermath of the earthquakes, Christchurch human service workers were contemplating their working lives based on a clearer articulation of what was truly meaningful to them. They expressed a desire for goodness of fit between personal beliefs and values, and for sustainable ethical workplace practices.

\section{Conclusion}

Human service work in the post-disaster environment has been demanding, and, by late 2011, participants were becoming increasingly exhausted. They commended managers that made efforts to protect them from demand overload, and foreshadowed burnout if ongoing needs were overlooked. They expressed admiration for efforts to prioritise staff wellbeing over profit, and expressed dissatisfaction when senior executives appeared disingenuous in their communications or made decisions without genuine consultation. While most were not currently looking for alternative work, they were involved in a meaning making process in which they sought to balance their personal and professional lives.

\section{References}

Brooker, J. (2011, March 10). Pain, misery for forgotten victims. The New Zealand Herald. Retrieved from http:/ / www.nzherald.co.nz.

Clarke, A. E. (2005). Situational analysis: Grounded theory after the postmodern turn. London: Sage.

Dwyer, S. (2007). The emotional impact of social work practice. Journal of Social Work Practice, 21(1), 49-60. doi: $10.1080 / 02650530601173607$.

Glaser, B. G., \& Strauss, A. (1967). The discovery of grounded theory: Strategies for qualitative research. Chicago, IL: Aldine.

Guo, Y.-J., Chen, C.-H., Lu, M.-L., Tan, H. K.-L., Lee, H.-W., \& Wang, T.-N. (2004). Posttraumatic stress disorder among professional and non-professional rescuers involved in an earthquake in Taiwan. Psychiatry Research, 127(1-2), 35-41. doi: 10.1016/j.psychres.2004.03.009.

Hartig, T., Johansson, G., \& Kylin, C. (2003). Residence in the social ecology of stress and restoration. Journal of Social Issues, 59(3), 611-636. doi: 10.1111/1540-4560.00080.

Health and Safety in Employment Amendment Act 2002. Retrieved from http: / www.legislation.govt.nz.

Hochwarter, W. A., Laird, M. D., \& Brouer, R. L. (2008). Board up the windows: The interactive effects of hurricane-induced job stress and perceived resources on work outcomes. Journal of Management, 34(2), 263-289. doi: $10.1177 / 0149206307309264$.

Klein, N. (2007). The shock doctrine: The rise of disaster capitalism. New York: Metropolitan Books.

Linzer, N., Sweifach, J., \& Heft-LaPorte, H. (2008). Triage and ethics: Social workers on the front line. Journal of Human Behavior in the Social Environment, 18(2), 184-203. doi: doi:10.1080/10911350802285896.

Lloyd, C., King, R., \& Chenoweth, L. (2002). Social work, stress and burnout: A review. Journal of Mental Health, 11(3), 255-266. doi: 10.1080/09638230020023642.

New Zealand Government. (2011, June 23). Latest Christchurch land information released [Press release]. Retrieved from http: / / www.scoop.co.nz / stories / PA1106/S00411/ latest-christchurch-land-information-released.htm.

Stylianou, G. (2012, February 10). Woman's death lifts earthquake toll to 185. The Press. Retrieved from http: / / www. stuff.co.nz/the-press.

Sullivan, S., \& Wong, S. (2011). An enhanced primary health care role following psychological trauma: The Christchurch earthquakes. Journal of Primary Health Care, 3(3), 248-251. Retrieved from http: / / www.rnzcgp.org.nz/ journal-of-primary-health-care/. 
Tosone, C., Nuttman-Shwartz, O., \& Stephens, T. (2012). Shared trauma: When the professional is personal. Clinical Social Work Journal, 40(2), 231-239. doi: 10.1007/ s10615-012-0395-0.

van Heugten, K. (2011). Social work under pressure: How to overcome stress, fatigue and burnout in the workplace. London: Jessica Kingsley.

van Heugten, K. (2012). Workplace stress in the aftermath of a natural disaster (New Zealand). In N. Hall (Ed.), Social work around the world V: Building the global agenda for social work and social development (V ed.) (pp. 41-52). Berne: IFSW Publications. 